\title{
The Efficacy and Safety of Postoperative Tranexamic Acid, Hemocoagulase Agkistrodon, and their Combination in Patients Undergoing Heart Valve Replacement With Cardiopulmonary Bypass
}

\author{
Jingxiu Chen \\ Sun Yat-sen University First Affiliated Hospital \\ Jingjie Li \\ Sun Yat-sen University Sixth Affiliated Hospital \\ Jiajia Yan \\ Sun Yat-sen University First Affiliated Hospital \\ Qiuyi He \\ Sun Yat-sen University First Affiliated Hospital \\ Min Huang \\ The School of Pharmaceutical Sciences, Sun Yat-Sen University \\ Xiao Chen \\ Sun Yat-sen University First Affiliated Hospital \\ Pan Chen ( $\nabla$ chenp73@mail.sysu.edu.cn ) \\ Sun Yat-sen University
}

Research

Keywords: tranexamic acid, hemocoagulase agkistrodon, cardiopulmonary bypass, cardiac valve replacement, efficacy, safety

Posted Date: November 22nd, 2021

DOI: https://doi.org/10.21203/rs.3.rs-1052954/v1

License: (c) (i) This work is licensed under a Creative Commons Attribution 4.0 International License. Read Full License 


\section{Abstract \\ Background}

Excessive bleeding is a major complication in patients undergoing cardiac surgery. We aimed to compare the efficacy and safety of postoperative tranexamic acid (TXA), hemocoagulase agkistrodon and their combination in patients undergoing heart valve replacement surgery with cardiopulmonary bypass (CPB).

\section{Methods}

This was a retrospective study. The enrolled patients were intravenously injected with TXA at a dose of $1.0 \mathrm{~g}$ during the intraoperative period. After surgery, the patients were assigned to four groups: the control group (Group C), the TXA group (Group T), the hemocoagulase agkistrodon group (Group H) and the combination group (Group TH). The primary efficacy outcomes were the total blood loss (TBL) from the time of the operation to postoperative Day 2 , postoperative blood loss within 2 days, and transfusion of red blood cells and plasma from the operation to postoperative Day 3 . The primary safety endpoint was the incidence of thromboembolic events.

\section{Results}

A total of 252 patients were recruited. There were no statistically significant differences in terms of the TBL, postoperative blood loss, volumes of red blood cells or plasma transfusion among the four groups. However, an increased total pericardial drainage volume and longer length of stay in the ICU were found in Group H compared with in Group T. In addition, increased volumes of total pericardial drainage were found in Group TH compared with Groups C and T. A similar result was also found in the number of days of pericardial drainage. Regarding safety outcomes, fibrinogen levels on postoperative Days 1 and 2 in Groups $\mathrm{H}$ and TH were significantly lower than those in Groups $\mathrm{C}$ and $\mathrm{T}$, while the frequencies of human fibrinogen transfusion in $\mathrm{Groups} \mathrm{H}$ and TH were higher, with the highest frequency in Group $\mathrm{H}$. The transfusions of human fibrinogen among Groups $\mathrm{C}, \mathrm{T}, \mathrm{H}$ and $\mathrm{TH}$ were $1.45 \%, 2.78 \%, 64.71 \%$, and $28.72 \%$, respectively. No significant differences were found in the postoperative incidences of thromboembolic events and acute kidney injuries among all groups.

\section{Conclusions}

Bleeding events after cardiac valve replacement surgery with CPB were not improved by postoperative administration of TXA, hemocoagulase agkistrodon or their combination. Hemocoagulase agkistrodon is related to hypofibrinogenemia and increased transfusions of human fibrinogen.

\section{Background}

Excessive bleeding is a major complication in patients undergoing cardiac surgery, which contributes to the need for blood transfusions and even reoperation for hemostasis [1, 2]. However, blood transfusions and second thoracotomy have been known to increase the risk of postoperative complications and even mortality [2-4]. Thus, measures using hemostatic agents to decrease perioperative bleeding are recommended. Nevertheless, there is a hypercoagulation state that occurs after surgery with a risk of thrombosis. The application of hemostatic agents should be performed cautiously and reasonably due to the possible induction of adverse reactions such as deep venous thrombosis, pulmonary embolism and cerebral embolism[5].

Tranexamic acid (TXA) and hemocoagulase are both widely used as hemostatic agents in China. As an antifibrinolytic agent, TXA blocks the lysine binding sites of plasminogen and inhibits its activation, which in turn prevents the degradation of fibrin to reduce blood loss [6-8]. Due to its broad applicability and minimal adverse reactions, TXA is recommended for clinical use by various guidelines associated with postpartum hemorrhage, trauma-associated hemorrhage and major hemorrhage [9-12]. On the other hand, hemocoagulase, a thrombin-like enzyme segregated and purified from snake venoms, plays a role in promoting coagulation mainly by stimulating platelet aggregation and accelerating thrombin and fibrin clot formation. Hemocoagulase has attracted increasing attention because of its advantages, such as low toxicity, quick and long-lasting action, and low levels of thrombosis [13, 14]. The hemocoagulase Agkistrodon Halys Palla (Hemocoagulase agkistrodon) is one of the hemocoagulase agents that has been prescribed in China. The postoperative use of hemocoagulase has been reported to reduce bleeding, although the evidence was relatively low [15-17].

Sufficient evidence has supported the use of TXA and hemocoagulase for the prophylaxis and treatment of bleeding during surgery and traumatic hemorrhage. However, a lack of valid evidence involves the effects of postoperative TXA and hemocoagulase, even though there are controversies associated with the results from the same or different types of surgeries [18-24]. Heart valve replacement is one of the surgeries with a high risk of blood loss [25], and it is clear that TXA has the ability to reduce perioperative blood loss and transfusions of blood products [26, 27], whereas it is not known whether additional postoperative TXA can further reduce bleeding. In addition, some studies have mentioned that the combined use of TXA and hemocoagulase enhanced the hemostasis effect and did not aggravate the occurrence of related adverse reactions, probably due to their actions in different coagulation processes [28-31]. However, it has not yet been characterized whether the postoperative combination is beneficial to patients with a high risk of both bleeding and thromboembolism after surgery.

Therefore, the present study comparatively evaluated the efficacy and safety of the postoperative use of TXA, hemocoagulase agkistrodon and their combination in patients undergoing heart valve replacement surgery with cardiopulmonary bypass (CPB) to provide a reference for postoperative hemostasis therapy. 
This retrospective study was carried out in the First Affiliated Hospital of Sun Yat-Sen University. Patients scheduled to undergo cardiac valve replacement with CPB from January 1, 2018 to January 1, 2020, were obtained. The study was approved by the Ethics Committee for Clinical Research and Animal Trails of the First Affiliated Hospital of Sun Yat-sen University.

The inclusion criteria were as follows: (1) patients undergoing cardiac valve replacement with CPB; (2) patients aged < 18 years; and (3) patients receiving intraoperative TXA at a dose of $1.0 \mathrm{~g}$.

The exclusion criteria were as follows: (1) Pregnant women; (2) Patients who died during the operation; (3) Intraoperative or postoperative administration of other antifibrinolytic agents or hemocoagulase; (4) $18 \mathrm{~h}$ postoperative usage of TXA or hemocoagulase agkistrodon or their combination; (5) Preoperative hemoglobin level <100 g/L; (6) Patients with coagulation disorders and hematological disorders; (7) Patients with a history of thromboembolism (including pulmonary embolism, renal infarction, myocardial infarction, hepatic infarction, stroke, deep venous thrombosis and so on), cirrhosis or severe renal failure (creatinine clearance rate $<25 \mathrm{ml} / \mathrm{min}$ ); (8) Patients that received emergency operations; and (9) The administration of the treatment didn't meet the requirement of each group (as mentioned in the following paragraph).

The enrolled patients were assigned to four groups according to the hemostatic drugs used within 6 hours after the surgery: the control group (Group C), TXA group (Group T), hemocoagulase agkistrodon group (Group H) and the combination group (Group TH). The patients in Group T were intravenously injected with $1.0 \mathrm{~g} / 100 \mathrm{~mL}$ TXA (Brilliant Pharmaceutical Group, China) within 6 hours after surgery. An additional single-bolus dose could be given between 6 and 18 hours after surgery. The patients in Group $\mathrm{H}$ were intravenously injected with hemocoagulase agkistrodon (Ahon Pharma, China) at a dose of $2 \mathrm{KU}$ within 6 hours after surgery. A second dose of $2 \mathrm{KU}$ could be given within 12 hours after the first dose. The patients in Group $\mathrm{C}$ received neither TXA nor hemocoagulase agkistrodon after surgery. The patients in Group TH received both TXA and hemocoagulase agkistrodon. A total of $2 \mathrm{KU}$ of hemocoagulase agkistrodon was dissolved in $20 \mathrm{ml}$ of $0.9 \%$ saline for the intravenous infusions. Intraoperative blood loss was graded as follows [28]: $\leq 750 \mathrm{~mL}$ for grade l; $>750 \mathrm{~mL}$ and $\leq 1500 \mathrm{~mL}$ for grade II; $>1500 \mathrm{~mL}$ and $\leq 2000 \mathrm{~mL}$ for grade III; and >2000 mL for grade IV.

\section{Outcome Measures}

The primary efficacy outcomes included total blood loss (TBL) from the time of the operation to postoperative Day 2, postoperative blood loss within 2 days, and the transfusion of red blood cells and plasma from the time of the operation to postoperative Day 3 . The overall pericardial drainage volume, number of days of pericardial drainage (days), length of intensive care unit (ICU) stay (hours), duration of mechanical ventilation (hours) and duration of postoperative hospitalization (days) were the secondary efficacy outcomes.

First, we calculated the estimation of total blood volume (ETBV) of each patient according to Moore's formula as follows: $E T B V_{\text {women }}(\mathrm{mL})=\mathrm{weight}(\mathrm{kg}) \times 65$; $\operatorname{ETBV}_{\text {men }}(\mathrm{mL})=$ weight $(\mathrm{kg}) \times 70$. Second, the estimation of TBL volume between the time of the operation and postoperative Day 2 was computed according to the following Gross's formula[32, 33]: TBL $=\mathrm{ETBV} \times \frac{\mathrm{Ht}_{0}-\mathrm{Ht}_{2}}{\left(\mathrm{Ht}_{0}-\mathrm{Ht}_{2}\right) / 2}\left(\mathrm{Ht}_{0}=\right.$ hematocrit before surgery; $\mathrm{Ht}_{2}=$ hematocrit second day after surgery). Finally, the volume of postoperative blood loss within 2 days was determined according to the following formula: postoperative blood loss=TBL-intraoperative blood loss. Intraoperative blood loss was recorded by a surgeon during the operation.

The primary safety endpoint was the incidence of thromboembolic events. The parameters of coagulation [activated partial thromboplastin time (APTT), prothrombin time (PT), the international normalized ratio (INR), fibrinogen (Fbg)], the hemogram [levels of red blood cells (RBC), hematocrit (Ht), hemoglobin $(\mathrm{Hb})$, and platelets (PLT)], and hepatic function [levels of alanine aminotransferase (ALT), aspartate aminotransferase (AST), and total bilirubin (TBIL)] on postoperative Days 1 and 2 and the incidence of acute kidney injury (AKI) were examined as secondary safety endpoints. AKI was defined as any of the following according to the 2012 KDIGO (Kidney Disease: Improving Global Outcomes) clinical practice guidelines [34]: increase in serum creatinine (SCr) by $\geq 26.5 \mu \mathrm{mol} / \mathrm{L}$ within 48 hours or increase in SCr to $\geq 1.5$ times baseline, which is known or presumed to have occurred within the prior 7 days.

\section{Statistical Analysis}

Continuous variables were described using the mean \pm standard deviation (SD) for normally distributed continuous data and compared using one-way analysis of variance, whereas the median and interquartile range (IQR) for nonnormally distributed continuous data were compared using the Kruskal-Wallis test. Categorical variables, shown as frequencies and percentages, were compared with the chi-square test, continuity correction chi-square test or Fisher's exact test. A P value of $<0.05$ was considered statistically significant. All statistical analyses were performed using Statistical Product and Service Solutions version 25.0 (IBM Corp., USA), and figures were made by GraphPad Prism 6 (GraphPad Software, La Jolla, CA).

\section{Results}

A total of 252 patients were finally enrolled according to the inclusion and exclusion criteria: 69 patients were assigned to Group C, 72 to Group T, 17 to Group $\mathrm{H}$ and 94 to Group TH (Figure 1). The demographic and operative characteristics of the patients are presented in Table 1 and were comparable among all groups $(P>0.05)$.

The TBL from the time of the operation to postoperative Day 2 of the four groups was 1454.84 (1082.29 2018.61) $\mathrm{mL}, 1460.20$ (1033.87 1911.08) $\mathrm{mL}$, 1579.59 (733.65 1942.96) $\mathrm{mL}$ and 1378.07 (1035.62 1836.00) $\mathrm{mL}$. Postoperative blood loss within 2 days was 888.63 (439.64 1418.61) $\mathrm{mL}, 907.79 \mathrm{~mL}$ (452.58 1366.44), 1279.59 (133.65 1542.96) $\mathrm{mL}$ and 808.62 (502.05 1333.49) $\mathrm{mL}$. The volume of red blood cell transfusion from the time of the operation to postoperative Day 3 was $2.00(1.50 \sim 4.00) \mathrm{U}, 3.50(2.00 \sim 4.00) \mathrm{U}, 4.00(0.00 \sim 4.00) \mathrm{U}$, and $4.00(2.00 \sim 4.00) \mathrm{U}$. The median plasma transfusion volume in 
any group was $400 \mathrm{~mL}$. There were no statistically significant differences in terms of the TBL, postoperative blood loss, volumes of red blood cells or plasma transfusion $(P>0.05)$ (Table 2).

The total pericardial drainage volumes of the four groups were $660.00 \mathrm{~mL}(510.00 \sim 815.00), 580.00(426.50 \sim 827.50) \mathrm{mL}, 815.87(770.00 \sim 935.00) \mathrm{mL}$, and 910.00 (700.00 1250.00) mL. The number of days of pericardial drainage were $4(4.00 \sim 6.00) \mathrm{d}, 4(4.00 \sim 5.18) \mathrm{d}, 5(4.00 \sim 7.00) \mathrm{d}$, and $6(4.00 \sim 7.00) \mathrm{d}$. The lengths of stay in the ICU were $19.70(18.70 \sim 38.30)$ h, $18.90(17.85 \sim 34.10)$ h, 37.90 (19.60 43.40) h, and 22.00 (18.30 40.60) h. Increased total pericardial drainage volumes and longer lengths of stay in the ICU were found in Group H compared with Group T $(P<0.05)$. In addition, increased volumes of total pericardial drainage were found in Group TH compared with Groups $C$ and T $(P<0.05)$. A similar result was also found in the number of days of pericardial drainage $(P<0.05)$. There were no significant differences in the duration of mechanical ventilation or length of stay in postoperative hospitalization among these groups $(P>0.05)$ (Table 3 ).

The levels of Fbg on postoperative Day 1 in the four groups were $2.94(2.48 \sim 3.40) \mathrm{g} / \mathrm{L}, 2.99(2.71 \sim 3.37) \mathrm{g} / \mathrm{L}, 1.30$ (0.95 1.61) g/L, and 1.65 (1.40 1.92) g/L. The levels of Fbg on postoperative Day 2 in the four groups were $4.72(4.19 \sim 5.01) \mathrm{g} / \mathrm{L}, 4.81(4.16 \sim 5.22) \mathrm{g} / \mathrm{L}, 2.80(2.17 \sim 3.60) \mathrm{g} / \mathrm{L}$, and $2.79(2.12 \sim 3.49) \mathrm{g} / \mathrm{L}$. Fbg levels on postoperative Days 1 and 2 in Groups $\mathrm{H}$ and TH were both lower than those in Groups $\mathrm{C}$ and $\mathrm{T}(P<0.001)$ (Table 4 and Figure 2). Human fibrinogen was transfused when patients presented with hypofibrinogenemia. The transfusion rates of human fibrinogen among the four groups were $1.45 \%$, $2.78 \%, 64.71 \%$, and $28.72 \%$. Compared with Groups $\mathrm{C}$ and T, the incidences of human fibrinogen transfusion in Groups $\mathrm{H}$ and TH were higher. The number of patients transfused with human fibrinogen in Group H was greater than that in Group TH $(P<0.001)$ (Table 5). PT on postoperative Day 1 was lower in Group $\mathrm{TH}$ than in Group T (13.30 s versus $14.20 \mathrm{~s}, P<0.05)$. APTT on postoperative Day 2 was lower in Group TH [34.65 (31.60 39.00) s] than in Group C [37.00 (34.50 41.40) s] and Group T [38.31 (34.10 42.80) s] $(P<0.05)$ (Table 4). Moreover, the TBIL level on postoperative Day 1 was lower in Group TH (31.80 $\mu \mathrm{mol} / \mathrm{L})$ than in Group C $(24.60 \mu \mathrm{mol} / \mathrm{L})(P<0.05)$ (Table 5). There were no significant differences in INR, PLT, Hb, RBC, Ht, ALT or AST levels among the groups at any other time point $(P>0.05)$ (Table 6 and Table 7). In addition, the postoperative incidences of thromboembolic events and AKI in all groups were similar $(P>0.05)$ (Table 8).

\section{Discussion}

CPB is a nonphysiological procedure that can induce the activation of platelet dysfunction, the fibrinolytic system, and the systemic inflammatory response, leading to an increased risk of perioperative bleeding[1,35]. Tissue plasminogen activator (t-PA), as a major activator of plasminogen, is able to convert plasminogen to plasmin, in turn lysing fibrin. Prior studies have demonstrated that with the setting of CPB, t-PA secretion has an immediate sustained increase, leading to the generation of plasmin along with the degradation of fibrin, increasing 10 - to 20 -fold during CPB, which is associated with excessive bleeding. As an antifibrinolytic agent, TXA has the ability to mitigate the state of hyperfibrinolysis. Plasminogen activator inhibitor 1 (PAl-1), an inhibitor of plasmin formation, secretes much less plasmin than t-PA during CPB. Nevertheless, the secretion of PAl-1 increases rapidly after 30 min into CPB and continues to rise 15 -fold compared to baseline by $2 \mathrm{~h}$ postoperatively, while the active t-PA level gradually falls [35-38]. These changes in t-PA and PAl-1 activities are likely to last from the first to the second postoperative day, thus leading to a hypofibrinolytic state and likely increasing the risk of thromboembolic events, such as early graft occlusion of the coronary artery [38, 39].

In our study, we found no statistically significant differences in terms of the TBL, postoperative blood loss, volumes of red blood cells and plasma transfusion, total drainage, days of drainage, length of ICU stay, duration of mechanical ventilation or duration of postoperative hospitalization between Groups $\mathrm{C}$ and $\mathrm{T}$, which indicated that the additional TXA postoperatively did not improve bleeding on the basis of intraoperative TXA. As a result, we concluded that there was no need for postoperative TXA in heart valve replacement surgery with CPB, which was mainly related to the hypofibrinolytic state occurring after surgery, as mentioned above. A previous study found that perioperative use of TXA was protective against fibrinolysis and that fibrinolytic resistance continued for up to $6 \mathrm{~h}$ after cardiac surgery. The fibrinolytic activities of the majority of patients almost normalized $48 \mathrm{~h}$ postoperatively [40], which may also explain the lack of a need for additional TXA administration after heart valve replacement surgery with CPB. However, the fibrinolytic response to CPB is heterogeneous, with individual differences among patients. Approximately one-third of patients show no change in PAl-1 activity or t-PA activity postoperatively [41]. Consequently, monitoring the fibrinolysis level during the perioperative period is necessary.

The CRASH-2 trial [42] concluded that TXA should be administered as soon as possible to trauma patients with significant hemorrhage because the administration of TXA after $3 \mathrm{~h}$ seemed to be less effective and even increased the risk of death due to bleeding. In our study, the minimum lengths of surgery in Groups T and TH were $200 \mathrm{~min}$ and $180 \mathrm{~min}$, respectively, both longer than $3 \mathrm{~h}$. The results showed that additional TXA after cardiac valve replacement surgery did not improve bleeding, which was, to some extent, consistent with the results of the CRASH-2 study. However, owing to the limited conditions, our study did not take into consideration continuous massive hemorrhage after surgery, such as bright red fluid in a large amount that was discharged from the pericardium, which might influence our results. In this case, TXA can be administered as soon as possible for hemostasis according to the fibrinolysis level and severity of the patient's state.

The instructions for hemocoagulase agkistrodon injection (BT) show that hemocoagulase agkistrodon with a strongly degradative effect of fibrinogen at large doses (50 100 KU) can markedly reduce the plasma fibrinogen level. Xu et al. [43] demonstrated that a significant decline in fibrinogen levels was observed in 11 patients with hematological disorders following extended exposure (longer than 7 days) to hemocoagulase agkistrodon. Furthermore, after the withdrawal of this drug, the low level of fibrinogen began to increase gradually. Nevertheless, Qi et al. [44] concluded that the rate of plasma fibrinogen reduction related to hemocoagulase agkistrodon was $14.28 \%$, which mainly occurred 6 hours after the administration of this agent, even at a normal dose. Moreover, another study including 91 patients discovered that even a small dose $(2 \mathrm{KU} / \mathrm{d})$ or short duration (one day) of receiving hemocoagulase agkistrodon could result in hypofibrinogenemia [45]. 
The dose and time of hemocoagulase agkistrodon in the present study were less than $4 \mathrm{KU}$ and 24 hours, respectively. The results showed that the fibrinogen levels on postoperative Days 1 and 2 in Group $\mathrm{H}$ were both lower than those in Group $\mathrm{C}$. In addition, increased postoperative fibrinogen infusions were found in Group $\mathrm{H}(64.71 \%)$ than in Groups $\mathrm{C}(1.45 \%)$ and $\mathrm{T}(2.78 \%)(P<0.05)$, which indicated that a small dose $(2 \mathrm{KU} / \mathrm{d})$ or short duration of hemocoagulase agkistrodon after surgery could contribute to a decrease in plasma fibrinogen, which was consistent with the results of previous studies. The mechanism is probably related to the process of fibrinolysis. Hemocoagulase agkistrodon is able to turn fibrinogen into fibrin monosomic I and accelerate the formation of blood clots, along with its ability to consume fibrinogen, which may lead to hypofibrinogenemia. Moreover, cardiac valve replacement surgery is a high-risk factor for bleeding that may aggravate the occurrence of hypofibrinogenemia. Consequently, frequent monitoring of plasma fibrinogen levels should be performed to decrease blood loss when prescribing hemocoagulase agkistrodon.

The fibrinogen level on postoperative Day 1 in Group TH was significantly lower than that in Group T but higher than that in Group H, although the difference was not significant $(P>0.05)$. Additionally, the patients in Group TH received a lower incidence of human fibrinogen infusions than patients in Group $\mathrm{H}(P<$ 0.05). Most patients in both groups recovered to the normal fibrinogen level $(2 \sim 4 \mathrm{~g} / \mathrm{L})$ on postoperative Day $2(P>0.05)$. This indicated that the antifibrinolytic effect of TXA could slightly improve the hypofibrinogenemia caused by hemocoagulase agkistrodon.

There are some limitations of our study. First, this was a retrospective study, and some underlying factors, such as the effect of coadministered drugs, the method of anesthesia and hemostasis during surgery, may influence the final outcomes. Second, the sample size was relatively small, especially in Group $\mathrm{H}$ (17 patients enrolled), which may also lead to bias and imprecision of the results. Finally, the long-term safety of TXA, hemocoagulase agkistrodon and their combination after surgery has not been investigated. For example, the occurrence of deep vein thrombosis within 3 months or 1 year postoperatively should be further followed up.

\section{Conclusion}

We demonstrated no additive effect with respect to improvement of bleeding by postoperative administration of TXA, hemocoagulase agkistrodon and their combination in patients following cardiac valve replacement surgery with CPB. The postoperative use of TXA is relatively safe, whereas hemocoagulase agkistrodon induces hypofibrinogenemia and increases the transfusion rate of human fibrinogen. Further prospective studies with larger sample sizes are needed to verify the results.

\section{Declarations}

\section{Acknowledgments/Funding}

This study was financially supported by the Guangdong Basic and Applied Basic Research Foundation (2020A1515010138).

\section{Disclosure of Conflicts of Interest}

The authors declare no conflicts of interest that could appear to have influenced the submitted work.

\section{Data availability statement}

The data that support the findings of this study are available from the corresponding authors upon reasonable request.

\section{Author Contributions}

$\mathrm{PC}, \mathrm{XC}$ and $\mathrm{MH}$ contributed to conception and design of the study. JXC and JJY organized the database. JXC and JJL performed the statistical analysis. JXC wrote the first draft of the manuscript. JJL, PC and QYH wrote the sections of the manuscript. All authors contributed to manuscript revision, read, and approved the submitted version.

\section{References}

1. Alaifan T, Alenazy A, Xiang Wang D, Fernando SM, Spence J, Belley-Cote E, Fox-Robichaud A, Ainswoth C, Karachi T, Kyeremanteng K et al: Tranexamic acid in cardiac surgery: a systematic review and meta-analysis (protocol). BMJ Open 2019, 9(9):e028585.

2. Karkouti K, Wijeysundera DN, Yau TM, Beattie WS, Abdelnaem E, McCluskey SA, Ghannam M, Yeo E, Djaiani G, Karski J: The independent association of massive blood loss with mortality in cardiac surgery. Transfusion 2004, 44(10):1453-1462.

3. Vivacqua A, Koch CG, Yousuf AM, Nowicki ER, Houghtaling PL, Blackstone EH, Sabik JF, 3rd: Morbidity of bleeding after cardiac surgery: is it blood transfusion, reoperation for bleeding, or both? Ann Thorac Surg 2011, 91(6):1780-1790.

4. Colson PH, Gaudard P, Fellahi JL, Bertet H, Faucanie M, Amour J, Blanloeil Y, Lanquetot H, Ouattara A, Picot MC et al: Active Bleeding after Cardiac Surgery: A Prospective Observational Multicenter Study. PLoS One 2016, 11(9):e0162396.

5. Ho KM, Bham E, Pavey W: Incidence of Venous Thromboembolism and Benefits and Risks of Thromboprophylaxis After Cardiac Surgery: A Systematic Review and Meta-Analysis. J Am Heart Assoc 2015, 4(10):e002652-e002652.

6. Astedt B: Clinical pharmacology of tranexamic acid. Scand J Gastroentero/ Supp/ 1987, 137:22-25.

7. Cai J, Ribkoff J, Olson S, Raghunathan V, Al-Samkari H, DeLoughery TG, Shatzel JJ: The many roles of tranexamic acid: An overview of the clinical indications for TXA in medical and surgical patients. Eur J Haematol 2020, 104(2):79-87.

Loading [MathJax]/jax/output/CommonHTML/fonts/TeX/fontdata.js n Surgery and Other Indications. DRUGS 1999, 57(6):1005-1032. 
9. Sentilhes L, Vayssiere C, Deneux-Tharaux C, Aya AG, Bayoumeu F, Bonnet MP, Djoudi R, Dolley P, Dreyfus M, Ducroux-Schouwey C et al: Postpartum hemorrhage: guidelines for clinical practice from the French College of Gynaecologists and Obstetricians (CNGOF): in collaboration with the French Society of Anesthesiology and Intensive Care (SFAR). Eur J Obstet Gynecol Reprod Biol 2016, 198:12-21.

10. Munoz M, Stensballe J, Ducloy-Bouthors AS, Bonnet MP, De Robertis E, Fornet I, Goffinet F, Hofer S, Holzgreve W, Manrique S et al: Patient blood management in obstetrics: prevention and treatment of postpartum haemorrhage. A NATA consensus statement. Blood Transfus 2019, 17(2):112-136.

11. Spahn DR, Bouillon B, Cerny V, Duranteau J, Filipescu D, Hunt BJ, Komadina R, Maegele M, Nardi G, Riddez L et al: The European guideline on management of major bleeding and coagulopathy following trauma: fifth edition. Critical Care 2019, 23(1).

12. Hunt BJ, Allard S, Keeling D, Norfolk D, Stanworth SJ, Pendry K: A practical guideline for the haematological management of major haemorrhage. British Journal of Haematology 2015, 170(6):788-803.

13. Yao Y-T, Yuan X, Fang N-X: Hemocoagulase reduces postoperative bleeding and blood transfusion in cardiac surgical patients. Medicine 2019, 98(52).

14. WU Guangtong ZX, SHI Yulan: Haemostasis mechanism of action of hemocoagulase for injection. CHINA MEDICAL HERALD 2011, 8(11):47-49.

15. Ding ST, Zhao P, L(u) JJ, Xing ND, Niu ZH, SUN Hui, WU Hai-hu, Ding-qi S: Hemostatic effect of hemocoagulase used in bladder irrigation and intravesical instillation after transurethral resection of the prostate. Journal of Shandong University (Health Science) 2012, 50(10):93-96.

16. Zhao H, Li ZC, Li HL, Zhou CH, Jian-ning Z: Clinical trial of haemocoagulase agkistrodon application after operation. Chin J Clin Pharmaco/2017, 033(013):1205-1206,1211.

17. Chen X, Zou YF, Chen YF, Xu-tao L: Study on the effect of hemocoagulase Agkistrodon application after abdominal surgery. Journal of Clinical Medical 2016, 3(030):5924-5926.

18. Wang Ti-hui WX, Wang Xiao-lu, Wu Jin-qing, Chen Ji-liang: Comparison of intra-articular injection of tranexamic acid versus hemocoagulase in total knee Chinese Journal of Joint Surgery(Electronic Version) 2018, 12(3):52-57.

19. Guo Yan-ping, Bo C: Cesarean Section at Local Joint Venous Blood Clotting Enzyme Application in the Operation Effect is Observed. Journal of Heze Medical College 2017, 29(2):22-24.

20. Xiao-liang H: Hemocoagulase in extracorporeal circulation in heart surgery hemostatic curative effect observation. Qinghai university; 2015.

21. Liu Zhen XP, Yang Jin, Qi Wei, Qi Fan: Restropective Study of Effect of Postoperative Additional Tranexamic Acid on Blood Loss in Total Knee Arthroplasty. Chinese Journal of Pharmacoepidemiology 2019, 28(1):23-26.

22. Lyu Zhan-bing RX-h, Cheng Fei, Qiao Ning-ning: Effect of postoperative application of tranexamic acid on recovery and prognosis after unilateral total hip arthroplasty. Chinese Journal of Postgraduates of Medicine 2019, 42(12):1085-1089.

23. Tsukada S, Kurosaka K, Nishino M, Maeda T, Hirasawa N, Matsue Y: Intraoperative Intravenous and Intra-Articular Plus Postoperative Intravenous Tranexamic Acid in Total Knee Arthroplasty: A Placebo-Controlled Randomized Controlled Trial. J Bone Joint Surg Am 2020, 102(8):687-692.

24. Sun Q, Yu X, Wu J, Ge W, Cai M, Li S: Efficacy of a Single Dose and an Additional Dose of Tranexamic Acid in Reduction of Blood Loss in Total Knee Arthroplasty. The Journal of Arthroplasty 2017, 32(7):2108-2112.

25. Bell AD, Roussin A, Cartier R, Chan WS, Douketis JD, Gupta A, Kraw ME, Lindsay TF, Love MP, Pannu N et al: The use of antiplatelet therapy in the outpatient setting: Canadian Cardiovascular Society guidelines. Can J Cardiol 2011, 27 Suppl A:S1-59.

26. Task Force on Patient Blood Management for Adult Cardiac Surgery of the European Association for Cardio-Thoracic S, the European Association of Cardiothoracic A, Boer C, Meesters MI, Milojevic M, Benedetto U, Bolliger D, von Heymann C, Jeppsson A, Koster A et al: 2017 EACTS/EACTA Guidelines on patient blood management for adult cardiac surgery. J Cardiothorac Vasc Anesth 2018, 32(1):88-120.

27. Guo J, Gao X, Ma Y, Lv H, Hu W, Zhang S, Ji H, Wang G, Shi J: Different dose regimes and administration methods of tranexamic acid in cardiac surgery: a meta-analysis of randomized trials. BMC Anesthesio/ 2019, 19(1):129.

28. LIU Xun XC-s, CUI Ling-li, WU An-shi, YUE Yun: Blood-saving effect of combination of hemocoagulase artox for injection and tranexamic acid in patients undergoing off-pump coronary artery bypass grafting. Chinese Journal of Anesthesiology 2012, 32(008):958-960.

29. Nagabhushan RM, Shetty AP, Dumpa SR, Subramanian B, Kanna RM, Shanmuganathan R: Effectiveness and Safety of Batroxobin, Tranexamic Acid and a Combination in Reduction of Blood Loss in Lumbar Spinal Fusion Surgery. Spine 2018, 43(5):E267-E273.

30. Xu C, Wu A, Yue Y: Which is more effective in adolescent idiopathic scoliosis surgery: batroxobin, tranexamic acid or a combination? Arch Orthop Trauma Surg 2012, 132(1):25-31.

31. Jian-wu F: Effect of Combined Thrombin and Traneamic Acid in Reducing Blood Loss of Intertrochanal Fracture. Chinese Journal of Thrombosis and Hemostasis 2018, 024(003):483-485.

32. Gross JB: Estimating allowable blood loss: corrected for dilution. Anesthesiology 1983, 58(3):277-280.

33. Lopez-Picado A, Albinarrate A, Barrachina B: Determination of Perioperative Blood Loss: Accuracy or Approximation?Anesth Analg 2017, 125(1):280-286.

34. Palevsky PM, Liu KD, Brophy PD, Chawla LS, Parikh CR, Thakar CV, Tolwani AJ, Waikar SS, Weisbord SD: KDOQI US commentary on the 2012 KDIGO clinical practice guideline for acute kidney injury. Am J Kidney Dis 2013, 61(5):649-672.

35. Sniecinski RM, Chandler WL: Activation of the hemostatic system during cardiopulmonary bypass. Anesth Analg 2011, 113(6):1319-1333.

36. Shi J, Zhou C, Liu S, Sun H, Wang Y, Yan F, Pan W, Zheng Z: Outcome impact of different tranexamic acid regimens in cardiac surgery with cardiopulmonary bypass (OPTIMAL): Rationale, design, and study protocol of a multicenter randomized controlled trial. Am Heart $\mathrm{J} 2020,222: 147-156$.

37. Chandler WL, Velan T: Secretion of tissue plasminogen activator and plasminogen activator inhibitor 1 during cardiopulmonary bypass. Thromb Res 2003, 112(3):185-192. 
38. Chandler W: The effects of cardiopulmonary bypass on fibrin formation and lysis: is a normal fibrinolytic response essential? J Cardiovasc Pharmacol 1996, 27 Suppl 1:S63-68.

39. Rifon J, Paramo JA, Panizo C, Montes R, Rocha E: The increase of plasminogen activator inhibitor activity is associated with graft occlusion in patients undergoing aorto-coronary bypass surgery. Br J Haematol 1997, 99(2):262-267.

40. Tang M, Wierup P, Rea CJ, Ingerslev J, Hjortdal VE, Sorensen B: Temporal changes in clot lysis and clot stability following tranexamic acid in cardiac surgery. Blood Coagul Fibrinolysis 2017, 28(4):295-302.

41. Chandler WL, Fitch JC, Wall MH, Verrier ED, Cochran RP, Soltow LO, Spiess D: Individual variations in the fibrinolytic response during and after cardiopulmonary bypass. Thromb Haemost 1995, 74(5):1293-1297.

42. collaborators C-, Roberts I, Shakur H, Afolabi A, Brohi K, Coats T, Dewan Y, Gando S, Guyatt G, Hunt BJ et al: The importance of early treatment with tranexamic acid in bleeding trauma patients: an exploratory analysis of the CRASH-2 randomised controlled trial. Lancet 2011, 377(9771):1096-1101, 1101 e1091-1092.

43. Linglong X, Dijiong W: Prolonged Hemocoagulase Agkistrodon Halys Pallas Administration Induces Hypofibrinogenemia in Patients with Hematological Disorders: A Clinical Analysis of 11 Patients. Indian J Hematol Blood Transfus 2018, 34(2):322-327.

44. QI Zhen GD-hYC, YANG Hong-yi, PANG Ning, LIU Si-yuan, LI Xiao-yang: The analysis of 399 ADRs associated with hemocoagulase and the risk signals mining. Chinese Journal of Drug Application and Monitoring 2019, 016(005):278-282.

45. CHENG Qian-na FJ-h: Analysis of 91 cases of pulmonary tuberculosis hemoptysis with hypofibrinogenemia caused by hemocoagulase. Chinese Journal of Modern Drug Application 2020, 14(2):17-20.

\section{Tables}

Table 1 Patient Demographic and Surgical Characteristics

Characteristics Group

\begin{tabular}{|c|c|c|c|c|c|}
\hline \multirow[t]{2}{*}{ Characteristics } & & \multirow{2}{*}{ Value } \\
\hline & $C(n=69)$ & $T(n=72)$ & $H(n=17)$ & TH $(n=94)$ & \\
\hline Sex (female/male) & $35 / 34$ & $29 / 43$ & $6 / 11$ & $45 / 49$ & 0.480 \\
\hline Age (y) & $53(46 \sim 61)$ & $50(42 \sim 56)$ & $54(40 \sim 60)$ & $54(47 \sim 61)$ & 0.140 \\
\hline $\mathrm{BMI}\left(\mathrm{kg} / \mathrm{m}^{2}\right)$ & $22.67 \pm 3.16$ & $22.29 \pm 2.93$ & $23.14 \pm 2.96$ & $22.83 \pm 3.88$ & 0.696 \\
\hline Preoperative LVEF (\%) & $64(61 \sim 69)$ & $65(57 \sim 70)$ & $66(52 \sim 68)$ & $64(58 \sim 68)$ & 0.843 \\
\hline Preoperative CREA ( $\mu \mathrm{mol} / \mathrm{L})$ & $76.00(67.00 \sim 88.00)$ & $76.00(64.00 \sim 93.00)$ & $75.00(73.00 \sim 86.00)$ & $75.50(62.00 \sim 87.00)$ & 0.931 \\
\hline \multicolumn{6}{|l|}{ Comorbidities } \\
\hline Atrial fibrillation, no. (\%) & $21(30.43)$ & $26(36.11)$ & $4(23.53)$ & $34(36.17)$ & 0.669 \\
\hline Pulmonary hypertension, no. (\%) & $21(30.43)$ & 19 (26.39) & $5(29.41)$ & $24(25.53)$ & 0.907 \\
\hline Hypertension, no. (\%) & $6(8.70)$ & $6(8.33)$ & $1(5.88)$ & $13(13.83)$ & 0.552 \\
\hline $\begin{array}{l}\text { Intraoperative human fibrinogen transfusion, } \\
\text { no. (\%) }\end{array}$ & $43(62.32)$ & $52(72.22)$ & $12(70.59)$ & $49(52.13)$ & 0.055 \\
\hline $\begin{array}{l}\text { Intraoperative prothrombin complex } \\
\text { transfusion, no. (\%) }\end{array}$ & $35(50.72)$ & $38(52.78)$ & $12(70.59)$ & $45(47.87)$ & 0.386 \\
\hline \multirow[t]{2}{*}{ Duration of surgery (min) } & 300 & 300 & 300 & 290 & \multirow[t]{2}{*}{0.872} \\
\hline & $(260 \sim 325)$ & $(260 \sim 340)$ & $(260 \sim 370)$ & $(250 \sim 340)$ & \\
\hline Intraoperative blood loss (mL) & $\begin{array}{l}500.00 \\
(500.00 \sim 600.00)\end{array}$ & $\begin{array}{l}552.10 \\
(475.00 \sim 600.00)\end{array}$ & $\begin{array}{l}500.00 \\
(400.00 \sim 600.00)\end{array}$ & $\begin{array}{l}500.00 \\
(400.00 \sim 600.00)\end{array}$ & 0.818 \\
\hline \multicolumn{6}{|l|}{ Intraoperative blood loss classification, no. (\%) } \\
\hline I & $60(86.96)$ & $60(83.33)$ & $14(82.35)$ & $80(85.11)$ & \multirow[t]{2}{*}{0.928} \\
\hline II & $9(13.04)$ & $12(16.67)$ & $3(17.65)$ & $14(14.89)$ & \\
\hline \multicolumn{6}{|l|}{ Heart value replacement, no. (\%) } \\
\hline Single valve & $60(86.96)$ & $56(77.78)$ & $15(88.24)$ & $72(76.60)$ & \multirow[t]{2}{*}{0.267} \\
\hline Multiple valves & $9(13.04)$ & $16(22.22)$ & $2(11.76)$ & $22(23.40)$ & \\
\hline
\end{tabular}

$P<0.05$, is considered to denote significant differences.

Abbreviations: $\mathrm{C}=$ control; $\mathrm{T}=$ tranexamic acid group; $\mathrm{H}=$ hemocoagulase agkistrodon; $\mathrm{TH}=$ the combination of tranexamic acid and hemocoagulase agkistrodon; $\mathrm{BMI}=$ body mass index; $\mathrm{LVEF}=$ left ventricular ejection fraction; 


\begin{tabular}{|c|c|c|c|c|c|}
\hline \multirow[t]{2}{*}{ Blood transfusion } & \multicolumn{4}{|l|}{ Group } & \multirow[t]{2}{*}{$P$ value } \\
\hline & $C(n=69)$ & $T(n=72)$ & $H(n=17)$ & TH $(n=94)$ & \\
\hline Total blood loss (mL) & $\begin{array}{l}1454.84 \\
(1082.29 \sim 2018.61)\end{array}$ & $\begin{array}{l}1460.20 \\
(1033.87 \sim 1911.08)\end{array}$ & $\begin{array}{l}1579.59 \\
(733.65 \sim 1942.96)\end{array}$ & $\begin{array}{l}1378.07 \\
(1035.62 \sim 1836.00)\end{array}$ & 0.921 \\
\hline $\begin{array}{l}\text { Postoperative blood loss within } 2 \\
\text { days }(\mathrm{mL})\end{array}$ & $\begin{array}{l}888.63 \\
(439.64 \sim 1418.61)\end{array}$ & $\begin{array}{l}907.79 \\
(452.58 \sim 1366.44)\end{array}$ & $\begin{array}{l}1279.59 \\
(133.65 \sim 1542.96)\end{array}$ & $\begin{array}{l}808.62 \\
(502.05 \sim 1333.49)\end{array}$ & 0.895 \\
\hline Plasma (mL) & $400(200 \sim 600)$ & $400(375 \sim 600)$ & $400(300 \sim 600)$ & $400(350 \sim 600)$ & 0.387 \\
\hline Red blood cells (U) & $2.00(1.50 \sim 4.00)$ & $3.50(2.00 \sim 4.00)$ & $4.00(0.00 \sim 4.00)$ & $4.00(2.00 \sim 4.00)$ & 0.290 \\
\hline
\end{tabular}

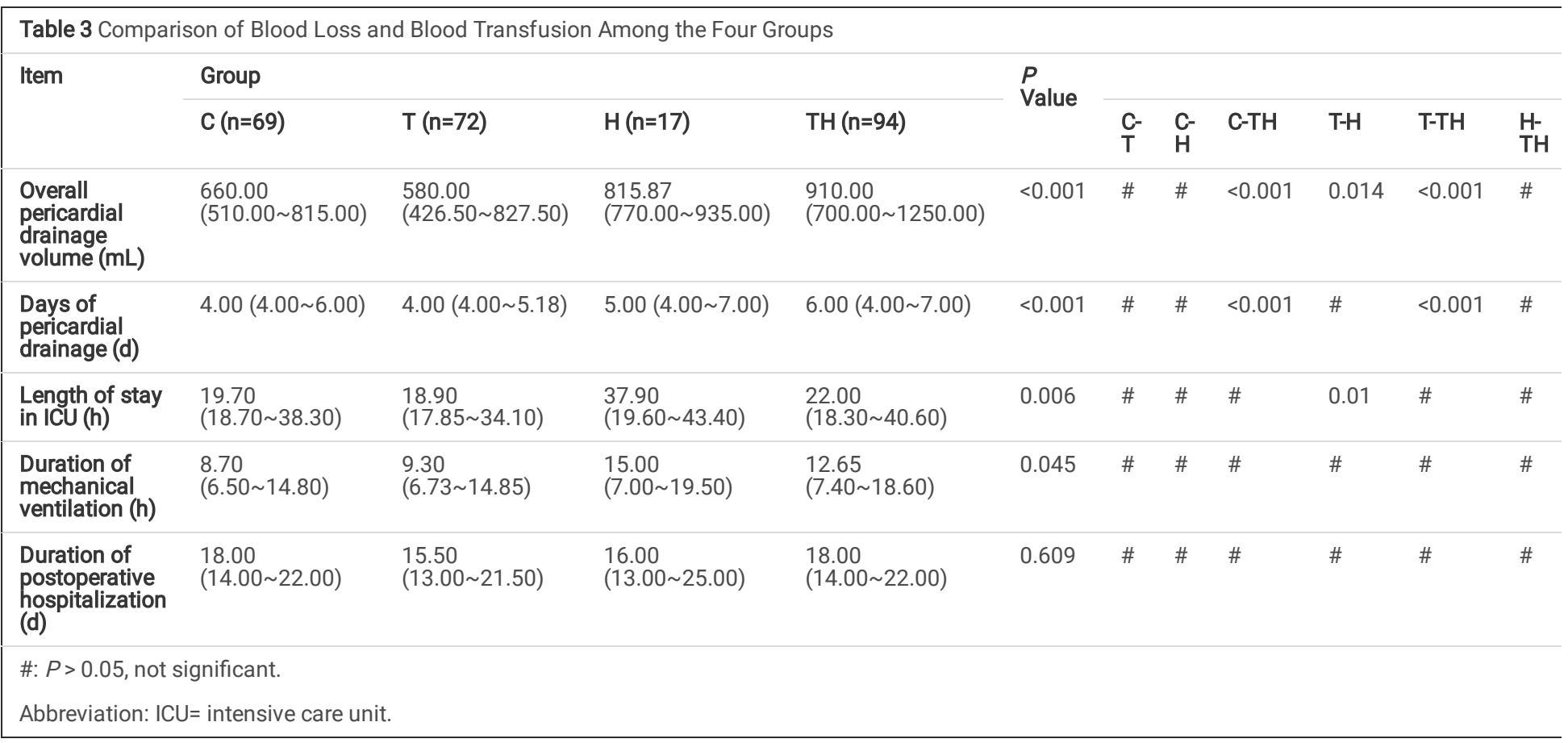




\begin{tabular}{|c|c|c|c|c|c|c|c|c|c|c|}
\hline \multicolumn{2}{|c|}{$\begin{array}{l}\text { Coagulation } \\
\text { index }\end{array}$} & \multicolumn{4}{|l|}{ Group } & \multirow{2}{*}{$\begin{array}{l}P \\
\text { Value }\end{array}$} & \multicolumn{4}{|c|}{ Pair wise $P$ value } \\
\hline & & $C(n=69)$ & $T(n=72)$ & $H(n=17)$ & $\mathrm{TH}(\mathrm{n}=94)$ & & $\frac{C-}{T}$ & $\mathrm{C}-\mathrm{H}$ & C-TH & $\mathrm{T}-\mathrm{H}$ \\
\hline \multirow[t]{3}{*}{$\begin{array}{l}\text { PT } \\
(s)\end{array}$} & $\begin{array}{l}\text { Post- } \\
0 \text { d }\end{array}$ & $14.60(13.10 \sim 15.70)$ & 13.85 (12.80 15.45) & 15.20 (13.70 16.40) & $14.50(13.30 \sim 15.80)$ & 0.218 & $\#$ & $\#$ & $\#$ & $\#$ \\
\hline & $\begin{array}{l}\text { Post- } \\
1 \mathrm{~d}\end{array}$ & $13.90(12.80 \sim 14.70)$ & $14.20(13.15 \sim 14.95)$ & 13.70 (12.50 16.50) & $13.30(12.30 \sim 14.50)$ & 0.040 & $\#$ & \# & $\#$ & $\#$ \\
\hline & $\begin{array}{l}\text { Post- } \\
2 \mathrm{~d}\end{array}$ & $13.30(12.60 \sim 14.70)$ & $13.60(12.50 \sim 14.25)$ & 12.90 (12.20 14.30) & $13.10(12.10 \sim 14.40)$ & 0.454 & $\#$ & $\#$ & $\#$ & $\#$ \\
\hline \multirow[t]{3}{*}{$\begin{array}{l}\text { APTT } \\
\text { (s) }\end{array}$} & $\begin{array}{l}\text { Post- } \\
0 \mathrm{~d}\end{array}$ & $35.70(33.10 \sim 38.30)$ & 35.15 (31.90 39.75) & 38.10 (31.60 39.80) & 35.05 (32.20 39.10) & 0.887 & $\#$ & $\#$ & $\#$ & $\#$ \\
\hline & $\begin{array}{l}\text { Post- } \\
1 \mathrm{~d}\end{array}$ & $35.20(30.90 \sim 38.40)$ & 35.10 (32.35 37.25) & 34.70 (33.70 37.90) & $33.50(30.10 \sim 36.90)$ & 0.108 & $\#$ & $\#$ & $\#$ & $\#$ \\
\hline & $\begin{array}{l}\text { Post- } \\
2 \mathrm{~d}\end{array}$ & $37.00(34.50 \sim 41.40)$ & $38.31(34.10 \sim 42.80)$ & $33.60(30.40 \sim 45.30)$ & $34.65(31.60 \sim 39.00)$ & 0.012 & $\#$ & $\#$ & 0.047 & $\#$ \\
\hline \multirow[t]{3}{*}{$\begin{array}{l}\mathrm{Fbg} \\
(\mathrm{g} / \mathrm{L})\end{array}$} & $\begin{array}{l}\text { Post- } \\
0 \mathrm{~d}\end{array}$ & 2.35 (1.89 2.61) & 2.32 (1.92 2.69) & 2.35 (1.97 2.49) & $2.22(1.94 \sim 2.57)$ & 0.941 & $\#$ & $\#$ & $\#$ & $\#$ \\
\hline & $\begin{array}{l}\text { Post- } \\
1 \mathrm{~d}\end{array}$ & $2.94(2.48 \sim 3.40)$ & 2.99 (2.71 3.37) & $1.30(0.95 \sim 1.61)$ & $1.65(1.40 \sim 1.92)$ & $<0.001$ & $\#$ & $<0.001$ & $<0.001$ & $<0.00^{\circ}$ \\
\hline & $\begin{array}{l}\text { Post- } \\
2 \mathrm{~d}\end{array}$ & $4.72(4.19 \sim 5.01)$ & $4.81(4.16 \sim 5.22)$ & $2.80(2.17 \sim 3.60)$ & 2.79 (2.12 3.49) & $<0.001$ & $\#$ & $<0.001$ & $<0.001$ & $<0.00^{\circ}$ \\
\hline \multirow[t]{3}{*}{ INR } & $\begin{array}{l}\text { Post- } \\
0 \text { d }\end{array}$ & $1.25(1.11 \sim 1.35)$ & $1.19(1.12 \sim 1.33)$ & $1.20(1.18 \sim 1.30)$ & $1.25(1.15 \sim 1.32)$ & 0.550 & $\#$ & $\#$ & $\#$ & $\#$ \\
\hline & $\begin{array}{l}\text { Post- } \\
1 \mathrm{~d}\end{array}$ & $1.16(1.08 \sim 1.20)$ & $1.15(1.09 \sim 1.21)$ & 1.19 (1.07 1.36) & $1.15(1.06 \sim 1.22)$ & 0.617 & $\#$ & $\#$ & $\#$ & $\#$ \\
\hline & $\begin{array}{l}\text { Post- } \\
2 \text { d }\end{array}$ & $1.14(1.09 \sim 1.26)$ & $1.14(1.08 \sim 1.21)$ & $1.12(1.05 \sim 1.21)$ & $1.13(1.04 \sim 1.25)$ & 0.716 & $\#$ & $\#$ & $\#$ & $\#$ \\
\hline
\end{tabular}

\#: $P>0.05$, not significant.

Abbreviations: APTT=activated partial thromboplastin time; PT=prothrombin time; Fbg=fibrinogen; INR=International Normalized Ratio;

\begin{tabular}{|c|c|c|c|c|c|}
\hline & \multicolumn{4}{|l|}{ Group } & \multirow[t]{2}{*}{$P$ valve } \\
\hline & C & $\mathbf{T}$ & $\mathrm{H}$ & $\mathrm{TH}$ & \\
\hline Postoperative human fibrinogen transfusion incidence (\%) & $1.45^{\mathrm{a}}$ & $2.78^{\mathrm{a}}$ & $64.71^{\mathrm{b}}$ & $28.72^{\mathrm{c}}$ & $<0.001$ \\
\hline
\end{tabular}




\begin{tabular}{|c|c|c|c|c|c|c|}
\hline & & \multicolumn{4}{|l|}{ Group } & \multirow[t]{2}{*}{$P$ value } \\
\hline & & $C(n=69)$ & $T(n=72)$ & $H(n=17)$ & TH $(n=94)$ & \\
\hline \multirow[t]{3}{*}{ PLT (x10^9/L) } & Post-0 d & $126.00(110.00 \sim 158.00)$ & $131.50(103.50 \sim 146.00)$ & $118.00(96.00 \sim 169.00)$ & $126.50(102.00 \sim 140.00)$ & 0.898 \\
\hline & Post-1 d & $112.00(92.00 \sim 146.00)$ & 121.00 (91.50 147.50) & $110.00(88.00 \sim 131.00)$ & $112.50(88.00 \sim 136.00)$ & 0.467 \\
\hline & Post-2 d & $102.00(85.00 \sim 130.00)$ & $112.78(95.00 \sim 133.50)$ & $102.00(91.00 \sim 118.00)$ & $111.50(85.00 \sim 136.00)$ & 0.613 \\
\hline \multirow{5}{*}{$\begin{array}{l}\mathrm{Hb} \\
(g / L)\end{array}$} & Post-0 d & 107.00 (99.00 115.00) & 106.00 (94.50 114.50) & 106.00 (98.00 112.00) & 107.00 (98.00 114.00) & 0.918 \\
\hline & Post-1 d & $96.00(91.00 \sim 106.00)$ & $100.00(93.00 \sim 108.00)$ & 98.00 & 96.50 & 0.823 \\
\hline & & & & $(88.00 \sim 107.00)$ & $(88.00 \sim 108.00)$ & \\
\hline & Post-2 d & $94.00(85.00 \sim 102.00)$ & 95.50 & 94.00 & 94.00 & 0.965 \\
\hline & & & $(86.00 \sim 101.00)$ & $(86.00 \sim 102.00)$ & $(82.00 \sim 105.00)$ & \\
\hline \multirow[t]{6}{*}{$\operatorname{RBC}\left(x 10^{\wedge} 12 / L\right)$} & Post-0 d & 3.66 & 3.54 & 3.57 & 3.67 & 0.498 \\
\hline & & $(3.43 \sim 4.11)$ & $(3.25 \sim 3.98)$ & $(3.37 \sim 3.85)$ & $(3.27 \sim 4.06)$ & \\
\hline & Post-1 d & 3.37 & 3.36 & 3.13 & 3.40 & 0.787 \\
\hline & & (3.02 3.83) & $(3.143 .80)$ & $(3.05 \sim 3.60)$ & $(3.04 \sim 3.70)$ & \\
\hline & Post-2 d & 3.27 & 3.26 & 3.09 & 3.28 & 0.787 \\
\hline & & $(2.93 \sim 3.59)$ & $(2.96 \sim 3.48)$ & $(2.81 \sim 3.55)$ & $(2.89 \sim 3.62)$ & \\
\hline \multirow[t]{6}{*}{$\mathrm{Ht}$} & Post-0 d & 0.31 & 0.31 & 0.31 & 0.32 & 0.288 \\
\hline & & $(0.29 \sim 0.34)$ & $(0.28 \sim 0.33)$ & $(0.30 \sim 0.33)$ & $(0.29 \sim 0.34)$ & \\
\hline & Post-1 d & 0.29 & 0.29 & 0.29 & 0.29 & 0.984 \\
\hline & & $(0.27 \sim 0.32)$ & $(0.27 \sim 0.31)$ & $(0.26 \sim 0.33)$ & $(0.26 \sim 0.32)$ & \\
\hline & Post-2 d & 0.28 & 0.28 & 0.29 & 0.28 & 0.972 \\
\hline & & $(0.26 \sim 0.31)$ & $(0.26 \sim 0.31)$ & $(0.26 \sim 0.31)$ & $(0.25 \sim 0.32)$ & \\
\hline
\end{tabular}

\begin{tabular}{|c|c|c|c|c|c|c|}
\hline & & \multicolumn{4}{|l|}{ Group } & \multirow[t]{2}{*}{$P$ value } \\
\hline & & $C(n=69)$ & $T(n=72)$ & $H(n=17)$ & TH $(n=94)$ & \\
\hline \multirow[t]{3}{*}{ ALT (U/L) } & Post-0 d & $34.00(24.00 \sim 40.00)$ & $29.00(23.00 \sim 38.00)$ & $33.00(24.00 \sim 36.00)$ & $31.50(26.00 \sim 40.00)$ & 0.210 \\
\hline & Post-1 d & $20.00(15.00 \sim 30.00)$ & $18.00(14.00 \sim 22.00)$ & $23.00(16.00 \sim 33.00)$ & $18.50(15.00 \sim 25.00)$ & 0.290 \\
\hline & Post-2 d & $18.00(14.00 \sim 29.00)$ & 18.00 (14.00 24.50) & 18.00 (15.00 27.00) & 19.00 (14.00 24.00) & 0.876 \\
\hline \multirow{3}{*}{$\begin{array}{l}\text { AST } \\
\text { (U/L) }\end{array}$} & Post-0 d & $77.00(57.00 \sim 95.00)$ & $67.00(55.00 \sim 81.50)$ & $69.00(55.00 \sim 75.00)$ & $70.00(53.00 \sim 93.00)$ & 0.407 \\
\hline & Post-1 d & $81.00(57.00 \sim 103.00)$ & $68.00(57.00 \sim 82.50)$ & $74.00(55.00 \sim 82.00)$ & $76.00(53.00 \sim 96.00)$ & 0.201 \\
\hline & Post-2 d & $53.00(38.00 \sim 71.00)$ & $47.00(37.50 \sim 56.00)$ & $54.00(43.00 \sim 62.00)$ & $51.50(34.00 \sim 68.93)$ & 0.610 \\
\hline \multirow[t]{3}{*}{ TBIL $(\mu \mathrm{mol} / \mathrm{L})$} & Post-0 d & $30.60(22.50 \sim 39.10)$ & $31.35(24.50 \sim 37.75)$ & $27.30(22.50 \sim 36.70)$ & $33.55(25.20 \sim 43.10)$ & 0.213 \\
\hline & Post-1 d & $24.60(18.10 \sim 35.20)$ & $25.15(19.15 \sim 36.00)$ & $25.90(22.90 \sim 33.50)$ & 31.80 (23.30 41.50) & $0.015^{\star}$ \\
\hline & Post-2 d & $19.40(14.40 \sim 28.10)$ & $19.50(13.95 \sim 26.00)$ & $20.70(16.90 \sim 25.50)$ & 20.80 (15.60 27.70) & 0.447 \\
\hline \multicolumn{7}{|l|}{$\star P<0.05$} \\
\hline \multicolumn{7}{|c|}{ Abbreviations: $\mathrm{ALT}=$ alanine aminotransferase; $\mathrm{AST}=$ aspartate aminotransferase, $\mathrm{TBI}=$ =total bilirubin. } \\
\hline
\end{tabular}




\begin{tabular}{|c|c|c|c|c|c|}
\hline & \multicolumn{4}{|l|}{ Group } & \multirow[t]{2}{*}{$P$ value } \\
\hline & $C(n=69)$ & $T(n=72)$ & $H(n=17)$ & TH $(n=94)$ & \\
\hline Incidence of thromboembolic events (n, \%) & $0(0.00)$ & $1(1.39)$ & $0(0.00)$ & $1(1.06)$ & 1 \\
\hline The postoperative incidence of acute kidney injury $(n, \%)$ & $13(18.84)$ & $7(9.72)$ & $0(0.00)$ & $18(19.15)$ & 0.074 \\
\hline
\end{tabular}

\section{Figures}

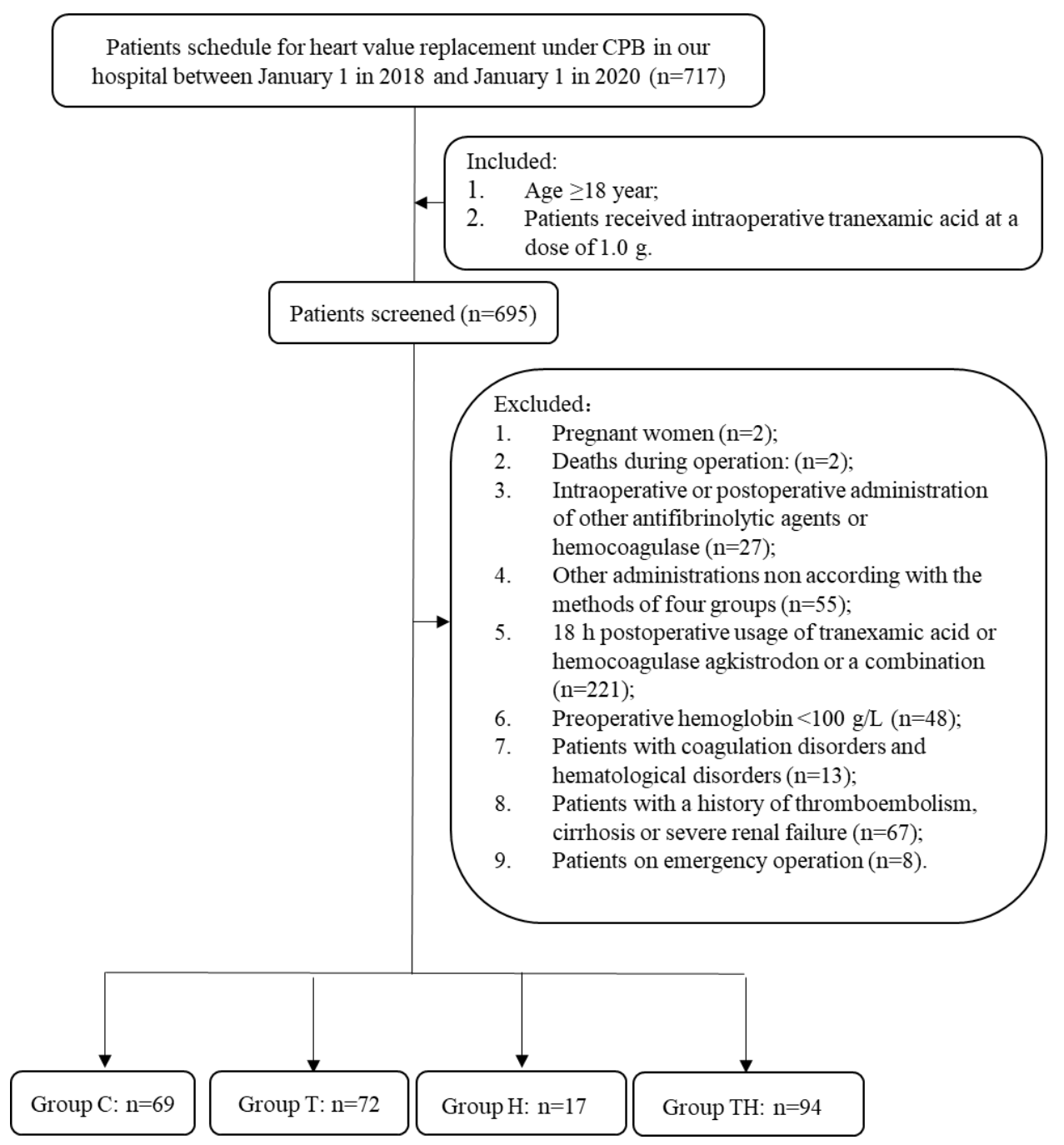

Figure 1

The process of patient inclusion. Abbreviations: $\mathrm{C}=$ control; $\mathrm{T}=$ tranexamic acid group; $\mathrm{H}=$ hemocoagulase agkistrodon; $\mathrm{TH}=$ the combination of tranexamic acid and hemocoagulase agkistrodon. 


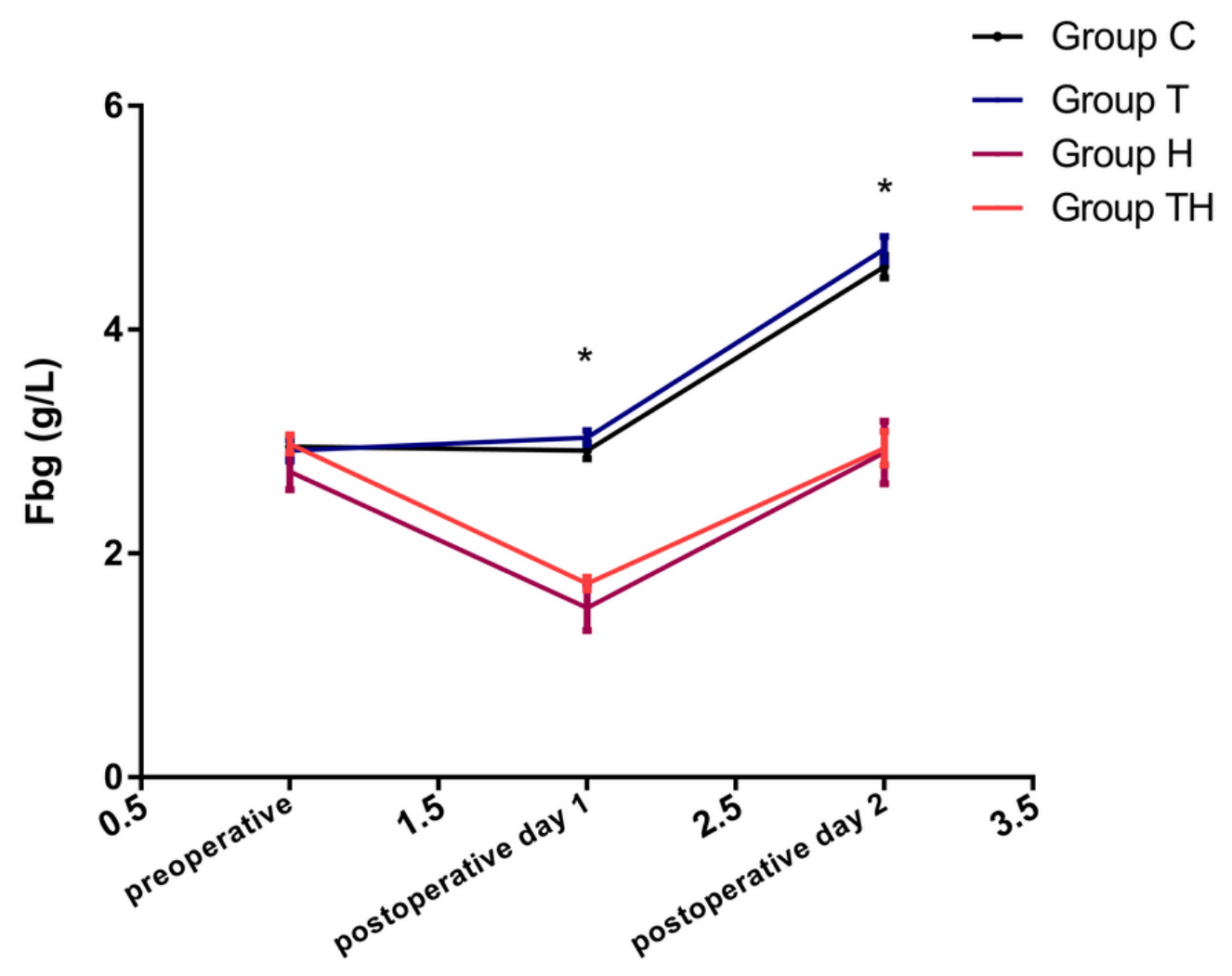

Figure 2

The change in the Fbg level at different time periods before and after surgery. $\mathrm{C}=$ control; $\mathrm{T}=$ tranexamic acid group; $\mathrm{H}=$ hemocoagulase agkistrodon; $\mathrm{TH}=$ the combination of tranexamic acid and hemocoagulase agkistrodon. * Fbg levels in Groups $\mathrm{H}$ and $\mathrm{TH}$ were both higher than those in $\mathrm{Groups} \mathrm{C}$ and $\mathrm{T}$ ( $\mathrm{P}<0.05$ ). Values are given as the mean \pm standard deviation. 